\title{
The Construction of Discipline Groups in the Characteristic Development of Application-oriented Institutes
}

\author{
Gen-yin $\mathrm{CHENG}^{1,2}$, Jing-jing TANG ${ }^{2,{ }^{*}}$, Jian $\mathrm{CAO}^{2}$, Jie-hua DING ${ }^{2}$ \\ and Shan FENG ${ }^{2}$ \\ ${ }^{1}$ Department of Safety Training of North China Institute of Science and Technology \\ Sanhe, Hebei 065201, China \\ ${ }^{2}$ College of Safety Engineering North China Institute of Science and Technology \\ Sanhe, Hebei 065201, China
}

Keywords: North China Institute of Science and Technology, Characteristic development, Safety of science and technology, Discipline groups.

\begin{abstract}
In the characteristic development of the application-oriented institutes, North China Institute of Science and Technology(NCIST) has always adhere to the safety in production and coal industry as the first service-oriented. After taking the construction of safety engineering discipline as a leader and designing and guiding discipline groups construction from the level of theoretical and conceptual, system, structural and mechanism, it has formed the safety engineering discipline groups, the soft science of safety discipline groups and the relative discipline groups. Advanced disciplines have become more remarkable by the construction of discipline groups and they have promoted the development of non-advanced disciplines to improve the core competitiveness of colleges and to make a useful exploration in the construction of discipline groups in characteristic development of application-oriented institutes.
\end{abstract}

\section{Introduction}

Studying the characteristics development of domestic universities started in the year of 2000. After the university system reform, many colleges and universities which belonged to original ministries faced with difficulties and problems in the transition process of development. Some of the original college level to undergraduate level schools simple pursuit the size of school and the number of disciplines, making the situation of "1000 schools all the same style", thereby causing reflection from university administrators and academics. However, "industry characteristic universities with a high level" includes only parts of the original key universities and colleges which placed under the Ministry of Education or the local after the Higher Education System Reform. Some institutions which cannot be called "high-level" but with industry characteristic, discipline characteristic or local characteristic can be positioned as application-oriented institutes. Facing new challenges and opportunities, these institutions have to follow the road of running institutions of characteristic development.

NCIST was promoted to undergraduate institutions in 2002 and has made positive exploration on the characteristic development of application-oriented institutes, the construction of the science and technology of safety discipline, theoretical research and teaching and research practice. Finally it has formed a fundamental development pattern of characteristic development of the science and technology of safety.

\section{Significance of Discipline Groups}

The problems in modern social development are becoming more complex. A single 
discipline problem-solving approach has not adapted to the trend of development, and the problems of major projects require multiple disciplines to solve [1]. A number of disciplines formed a discipline groups with mutual infiltration and support. The construction of discipline groups is the basis for the characteristic development of application-oriented institutes. It is inseparable from the unique and advantages discipline groups if NCIST needs key point and a competitive advantage in the practice of characteristics development of application-oriented institutes. The actively building advanced discipline groups are the key and the inevitable choice of university characteristic development. It determines whether a university can obtain the relative competitive advantage with other similar universities or not. It is also the core and fundamental of sustainable development.

Discipline Groups are the new architecture of the knowledge system, the new ways of academic production, the new carriers of gathering resources and the new characteristics of universities development [2]. It can integrate a variety of educational resources, allocate efficient resources, share resources and optimize the discipline structure through the establishment of discipline groups. Blending different academic ideas and learning from each research methods help to generate new ideas and provide more valuable research topic. The advanced discipline drives other disciplines, so that the advanced discipline is more significant. Under the influence of the advanced discipline, discipline groups developed continuously, which can provide the conditions to train the applied talents who have a strong ability to adapt. Thus improved the overall level of scientific research and enhanced the core competitiveness. The unique value of discipline groups in scientific research, personnel training and social services, known as the new trends with the most significant breakthroughs in the discipline construction of our country's colleges and universities[3].

\section{Strategies of Discipline Groups Construction [4]}

The construction of discipline groups is not simple an addition. However it is based on the level of theoretical and conceptual, system, structural, mechanisms as follows to design and guide the construction of discipline groups.

\section{Theoretical and Conceptual Level}

The construction of discipline groups was to promote the integration of innovation knowledge and to enhance the core competitiveness of school. On the one hand, On the one hand access to development resources through a combination of disciplines and strive for projects. The more important characteristic is to integrate the school disciplines, forming the core competitiveness of the school development and laying the foundation for a long-term development of the school. On the other hand, larger groups formed by different schools of discipline groups conducive to the systematic and the integrity of discipline and promote the integrated innovation of knowledge. So it can collaborate with organizations and scholars outside the universities and develops the international communication.

\section{System Level}

The discipline system that includes the system of organizational, planning, the resource allocation, implementation, inspection and evaluation and rewards and penaltiesis the core of modern university system. Establishing discipline groups need to adhere to the academic standard and give full play to the collective wisdom of crowds on institutional arrangements; at the same time, standardizing behavior of 
academic scholars from different disciplines to ensure that the value of academic resources. However, it must prevent two tendencies: one is administrative tendency which formed hierarchical management system in accordance with the size of the administrative level; the other is that taking the project funding as the guidance from which the team dismissed after obtained financing to complete the transverse or longitudinal research. Finally it leads to lack of long-term institutional guarantee.

\section{Structural Level}

The discipline groups were divided into the following three categories according to the research on the organizational form of discipline groups by domestic scholars:

The first category which based on the form of the geometry was summarized the organizational form of discipline groups into five[5], namely the type of the tree, the type of network, the type of determinant, the type of star clusters and the type of atomic clusters. This is basically organized on the basis of the level of discipline and mutual relationship.

The second category summarized into three groups with the tightness of discipline groups combine, namely the entity type, compact type and the loose type.

The third category summarized the discipline groups into four types: the schools entity, the new group entity, the academic groups and the research aggregation.

The mainly mode of the world-class university's discipline construction is the organic unity of the main discipline, the core subjects, the support discipline and the specialties disciplines. This reflected on the complete discipline system in comprehensive, depend on the highlighting of discipline characteristics in excellent, and brought coordination between disciplines in vigor.

The construction of disciplines is spontaneous and lacks of rational planning of development in some domestic universities. Schools just did tracking research, but lacked originality and cutting-edge research. Aiming at the experience and deficiency in the foreign universities, we believe that: partitioning discipline showed the limitations for people knowing the world. However the construction of discipline groups is the process of integrating the various forms of knowledge and need to optimum combination in structure. The first layer of the basic framework of the discipline groups is its main direction, namely the core disciplines; the second is the main discipline, namely discipline which conjunction with the core disciplines very closely; the third is the support discipline which had potential influence on the development of core disciplines; the fourth is related disciplines which provided different ideas and methods for the core disciplines. This four-story frame eliminated the isolated boundaries of disciplines and formed a knowledge community.

\section{Mechanism Level}

The right to speak should be prominent for academics. Emphasizing those academics should communicate and cooperate with management and the social public. The construction of discipline groups is an interdisciplinary research activity, which significantly altered the science and the university disciplines in structure, layout and development prospects. The essence of interdisciplinary research is to re-organize and integrate knowledge. The university interdisciplinary research is an important manifestation of the development of university academic functions. Because of the market competition, the urgent need of survival and development of colleges and universities forced the management to consider the social demand conditions in the new discipline setting. It is an important criterion to measure the practical value and practical purposes for university established disciplines. Discipline construction in the 
level of mechanisms needs to highlight academic discourse with the combined effect in subject orientation, management orientation and market orientation, because the main subject of discipline groups activity is the scholars; as the same time stressed that academics should communicate and cooperate with management and the social public, including business and universities investors, sponsors, and reasonable deal with the relationship between the current interests and the long-term social benefits and academic value.

\section{Practice in the Construction of Discipline Groups of NCIST}

In order to build the application-oriented institutes with the characteristic of the science and technology of safety, NCIST carried out exploration and practice on the construction of discipline. Centering on the core disciplines, it has formed the main discipline, the support discipline and the related discipline of discipline community. At last, NCIST has built into the discipline groups of safety engineering, the discipline groups of soft science of safety and the discipline groups of correlation with the characteristic of the science and technology of safety. The specific discipline groups including disciplines are shown in the table 1.

Table 1.List of discipline construction

\begin{tabular}{|c|c|c|c|}
\hline Groups & Safety Engineering & Soft Science of Safety & Relative Discipline \\
\hline \multirow{7}{*}{ disciplines } & $\begin{array}{l}\text { safety technology and } \\
\text { engineering }\end{array}$ & safety philosophy & $\begin{array}{c}\text { electromechanical } \\
\text { engineering disciplines }\end{array}$ \\
\hline & mining engineering & safety law & $\begin{array}{l}\text { electronic information } \\
\text { discipline }\end{array}$ \\
\hline & $\begin{array}{l}\text { electromechanical Device } \\
\text { discipline }\end{array}$ & safety sociology & computer science \\
\hline & construction safety & safety economics & $\begin{array}{c}\text { constructional } \\
\text { engineering discipline }\end{array}$ \\
\hline & network security & safety supervision & $\begin{array}{l}\text { environmental } \\
\text { engineering discipline }\end{array}$ \\
\hline & safety materials science & safety culturology & management discipline \\
\hline & safety probing technique & safety managerialics & $\begin{array}{c}\text { humanistic society } \\
\text { discipline }\end{array}$ \\
\hline
\end{tabular}

\section{Safety Engineering Discipline Groups}

The key disciplines played a leading role and promoted and facilitated other relatively weak disciplines' development. Safety technology and engineering and mining engineering discipline have been the key disciplines. The NCIST made full use of leading discipline to optimize the combination of disciplines and to promote the development of electromechanical device discipline, construction safety, network security, safety materials science and safety probing technique which made the discipline groups of safety engineering with the characteristics of the science and technology of safety. At the leading of the key disciplines, three specialties of safety engineering, mining engineering and automation have been selected as characteristic specialty of national level, safety engineering specialty has obtained the funding from the comprehensive reform project of the Education Ministry, two specialties of geological engineering and mineral processing engineering has been the characteristic specialty of provincial brand and safety engineering has been approved as professional pilot of "education training plan for excellent engineer" by the Ministry of Education. 


\section{Soft Science of Safety Discipline Groups}

NCIST has taken on going theoretical research and practical exploration on characteristic disciplines of the science and technology of safety, made innovative achievements and formed discipline groups of soft science of safety. The "Safe Sociology" monograph which is the first safety sociology in domestic written by professor Yan Ye has been published by the China University of Political Science Press. In addition, Professor Liu Xing's ethics of safety research in the leading level in domestic. Professor Wei Liu's "Safety Economics" and Dr. Yi-fei Weng's "safety monitoring study" have been published. These research results are important progress in the construction of discipline groups of soft science of safety, and also provided a theoretical data for the characteristics of building the school.

\section{Relative Discipline Groups}

In the influence of achievements which were made by discipline groups of safety engineering and discipline groups of soft science of safety, and combined with other specialty characteristic, it has formed a related discipline groups that the disciplines showed in the table 1 above.

\section{Concluding Remarks}

Disciplines are an essential element to implement all work in NCIST and also the basis of the three main functions in personnel training. The construction of characteristic discipline groups of the science and technology of safety has initially accelerated the development of disciplines, improved the quality of talent cultivation increased the depth of academic research and enhance the ability of social services scientific research and promoted social services[6].

The construction of discipline groups is complicated. In order to perform effectively, achieve a leap in the construction and development of discipline groups, it needs to join forces together and cooperate, break with tradition and have new ideas, expand horizons, and keep a foothold long-term[7].In addition, it also needs to continue to explore and practice, centering on the frame of the core disciplines the main disciplines supporting the related disciplines to explore the organization of different discipline group, at the same time, getting experience and carrying out exchanges and cooperation with the same or similar backgrounds learn of domestic and international institutions which gained excellent results in the construction of discipline groups, to promote the construction of discipline groups with characteristics of the science and technology of safety more mature, so as to promote the characteristic development of application-oriented institutes of NCIST.

\section{Acknowledgement}

The authors thank the support of the fund project: The key projects of Hebei Province Higher Education Academy.

\section{References}

[1] Gang He. Brief discussion synergies of university discipline groups [J].China Higher Education Research, 2011, (12):32-34.

[2] Rendong Hu. Discussion on connotation features and construction strategy of University advantages discipline groups [J]. China Higher Education Research, 2011(08):50-53. 
[3] Jingxing Tan, Yangsu Zeng, Mengqian Chen. From Discipline to Discipline Froups: the Perspective of Knowledge Classification System and Knowledge Policy [J]. Study of Higher Education, 2007(7):31- 35.

[4] Genyin Cheng, BiZhang, You Chen. Characteristic Discipline Group of Safety Technology Construction in the Discipline Groups [J]. Journal of North China Institute of Science and Technology, 2014,11 (12).

[5] YongXuan, JianLing. University Construction of Discipline Systematization: Value and Path [J]. Educational Research, 2009, (08):31-37.

[6] Jun Pang, Yang Yang, Hongliang Tang. Construction of Advantages Discipline Group, Promote the Development of TCM Colleges and Universities Discipline [J]. Higher Education Forum, 2009(2)18-20.

[7] Jie Lin, Xuetao Piao. Study of the College Advantages Discipline Groups Construction Based on Characteristics Development-Taking Liaoning Province as an Example [J]. Study of Higher Education, 2011(7):59-62. 